\title{
Health Promoting Behaviors and Their Relationship With General Health in Menopausal Women of Langroud City
}

\author{
Fahimeh Sehhatie Shafaie ${ }^{1}$, Mojgan Mirghafourvand ${ }^{1}$, Kafiyeh Momeni ${ }^{2 *}$
}

\begin{abstract}
Objectives: Health promoting behaviors and healthy lifestyle are the main ways to maintain health. Wrong lifestyle in menopausal women is the reason of many serious side-effects of this period. On the other hand, health is undoubtedly the most important aspect of human life; therefore, this study was conducted to determine the state of health promoting behaviors and their relationship with general health in menopausal women in Langroud city, Gilan province in 2013.

Materials and Methods: In this cross-sectional study, 400 menopausal women at the age range of 45-60 living in Langroud were randomly selected. The data were collected using demographic questionnaire, Health Promoting Lifestyle Profile (HPLP-II) and General Health Questionnaire (GHQ-28) by referring to the houses. Statistical tests of Pearson, $t$ test, one-way analysis of variance (ANOVA) and multivariate linear regression were used to analyze data.

Results: Mean (standard deviation) of health promoting behaviors' total score was $2.6(0.3)$. The highest score of lifestyle was related to spiritual growth, $3.6(0.4)$, and the lowest score was related to physical activity, $1.6(0.3)$. Mean (standard deviation) of the total score of general health was 21.3 (6.9) and $26.7 \%$ of women were not in good health. There was a significant statistical relationship between health promoting behaviors and general health.

Conclusion: The results showed that health promoting behaviors in menopausal women were average; therefore, some solutions should be designed and performed for health promoting behaviors and general health in menopausal women in order to reach to favorable state.

Keywords: Behavior, Health, Menopause, Women
\end{abstract}

\section{Introduction}

One of the health determining criteria is health promoting behaviors recognized as the basic factor in preventing from diseases and health promotion and this prevention is directly related to these behaviors (1). According to the World Health Organization (WHO), 70\%-80\% of mortalities in developed countries and $50 \%-60 \%$ of mortalities in developing countries are related to lifestyle factors (2). Most of the health problems such as overweight, cancer, smoking, addiction and cardiovascular diseases are related to lifestyle varieties (3). Health promoting behaviors, by emphasizing on healthy lifestyle, promote health and life quality and decrease treatment expenses (4). The most important emphasis of health promotion is preventing from diseases and promoting and developing the skills and capabilities of individuals' self-care (5).

Health promoting behaviors are defined as continuous activities carried out based on active approach in order to maintain and promote personal welfare and self-actualization. In this respect, it is important to recognize personal factors and features of individuals that have role in continuing health promoting behaviors and also in structured interventions for promotions and maintaining these behaviors (6). Health promoting behaviors are multidimensional patterns divided into 6 dimensions of nutrition, physical activity, spiritual growth, health responsibility, stress management and interpersonal relations by Pender et al in 1996 (7). Focusing on healthy lifestyle in all stages of life is an undeniable necessity for having a dynamic and healthy life from embryonic period to old age. Menopause is one of the periods important to be focused to health promoting behaviors.

Ghuorbani et al studied health promoting behaviors and their relationship with hot flashes in menopausal women in Mashhad and showed that there was a relationship between health promoting behaviors and hot flashes (8). In their study in Fenland, Moilanen et al showed that athlete and non-alcoholic middle-aged women experience less side-effects of menopause in comparison with non-athlete and alcoholic women (9).

On the other hand, health is undoubtedly the most important aspect of human life and is the matter that human has attempted to reach from prehistoric era up to now. Health is the necessity for social roles and when an individual feels healthy and is felt healthy by the society, he/she can have a perfect role (10). It is one of the primary rights of human and necessary for the development of societies (11). General health is defined as physical, psychological and social reactions to internal and external stimuli (12). In 1979, Goldberg divided general health into 4 fields of physical health, anxiety, social function and depression. Nowadays, health systems set its important programs on 
family health and women are considered as the center of family health and women's health is one of the indices of society development; therefore, it is important to recognize women's needs, psychological and emotional features and their abilities in social and economic dimensions (13).

There are evidences representative of unfavorable states of women's health in the world while the main part of society's responsibilities such as health, health education and help in critical situations are carried out by women (14). The study by Shahrokhi about working women's general health in Ghazvin showed that women have general health disorder (15). In the study by Solhi et al in Chalous, 27\% of women had unfavorable general health (16). A study in Turkey by Karaçam and Şeker on menopausal women showed that problems of menopause affect women's health and life quality (17). This study evaluated health promoting behaviors and their relationship with general health in menopausal women.

\section{Materials and Methods}

This is a cross-sectional, descriptive and analytical study carried out on menopausal women of Langroud city in 2013. The samples were chosen by random cluster sampling. Considering 5\% error, accuracy of 0.05 and standard deviation of 0.36 of the total score of health promoting behaviors in the study by Enjezab et al (18), the sample size was calculated about 199 cases and regarding the design effect of 2 , the sample size was estimated 400 subjects for the study.

After getting the approval of the Ethics Committee of Research Deputy in Tabriz University of Medical Sciences (TUOMS), the researcher was introduced to Gilan University of Medical Sciences. After a complete explanation of the proposal, Research Deputy of Gilan University approved the study to be carried out. The researcher was introduced to health center of Langroud city for sampling. According to population information of statistical center of the health center, the number of middle-aged women was 8000 in Langroud. The researcher needed the address of 80 middle-aged women at the age range of 45 to 60 as head clusters. The statistical center of the health center let the researcher have access to the address so 80 women were randomly chosen as the head clusters. Sampling was carried out by random cluster sampling. At first, the researcher referred to the address of the women in menopause (the head clusters) and after explaining the proposal and its advantages, results and confidentiality of the information, written informed consent was taken and the questionnaire was filled through interview. Then, by moving to the left side, the questionnaire was filled for 5 subjects in each 80 clusters so it was filled for 400 subjects.

\section{Study Tools}

In this study, data were collected using demographic questionnaire, Health Promoting Lifestyle Profile-II (HPLPII) and General Health Questionnaire $(\mathrm{GHQ}=28)$. Demographic questionnaire included questions about age, menopause age, body mass index (BMI), education level, marital status, and number of children, number of family members, sadat status, working status, economic status, life satisfaction and having chronic diseases.

\section{Data Analysis}

Data were analyzed by SPSS version 13. Descriptive statistics such as absolute and relative frequency distributions and also central indices and distributions like mean and standard deviation (SD) were used for describing demographic features and health promoting behaviors status. For analyzing the relationship between health promoting behaviors and general health, at first bivariate tests like $t$ test, Pearson, and one-way analysis of variance (ANOVA) were used and then for controlling the confounding variables and estimating the effect of every independent variable (health promoting lifestyle) on dependent variable (general health) and variance explanation, the independent variables with $P$ value less than 0.2 in bivariate test entered into multivariate linear regression model with Backward strategy. $P$ less than 0.05 was considered significant.

\section{Results}

Demographic Features

Table 1 shows the demographic features of women who participated in the study. Means (SDs) of age and menopause age were 53 years (3.5) and 48.4 years (2.2), respectively. Almost one-fourth of women were overweight with BMI more than 30 and more than half of women suffered from at least one chronic disease. The education level of almost half of women was elementary school. More than $90 \%$ of women were married and more than half of them had 3 to 4 children. $74.7 \%$ of women were housewives. The samples were almost in equal states considering social and economic states. More than three-fourths of subjects (75.3\%) were in appropriate economic state and more than half of the subjects (53\%) were satisfied with their lives. More than half of the participants were satisfied with their life.

\section{Health Promoting Behaviors}

Table 2 shows the mean (SD) of the total score of health promoting behaviors and the subdomains. Mean (SD) of lifestyle in menopausal women was $2.6(0.3)$ and the highest score of behavioral dimension of lifestyle was related to spiritual growth, $3.6(0.4)$, and the lowest score was related to physical activity, $1.6(0.3)$.

The Relationship Between Lifestyle and General Health According to Pearson correlation coefficient, there was a reverse significant relationship between health promoting behaviors and the subdomains and the total score of general health $(P<0.05)$ (Table 3$)$.

\section{Discussion}

This study was carried out by the purpose of determining health promoting behaviors in menopausal women of Langroud city. The research showed that menopausal women had average lifestyle. The results of this study cor- 
Table 1. Demographic Characteristics of 45-60 Years Old Menopausal Women $(n=400)$

\begin{tabular}{|c|c|}
\hline Variables & Number (\%) \\
\hline \multicolumn{2}{|l|}{ Age (y) } \\
\hline$\leq 50$ & $101(25.3)$ \\
\hline $50-55$ & $184(46)$ \\
\hline$>55$ & $115(28.7)$ \\
\hline Mean (SD) & $53.3(3.5)$ \\
\hline Range of changes & $47-60$ \\
\hline \multicolumn{2}{|l|}{ Menopausal age (y) } \\
\hline $45-50$ & $330(82.5)$ \\
\hline$\geq 50$ & $70(17.5)$ \\
\hline Mean (SD) & $48.4(2.2)$ \\
\hline Range of changes & $45-55$ \\
\hline \multicolumn{2}{|l|}{ Body Mass Index $\left(\mathrm{kg} / \mathrm{m}^{2}\right)$} \\
\hline$<18.5$ & $2(0.5)$ \\
\hline $18.5-24.99$ & $75(18.8)$ \\
\hline $25-25.99$ & $224(56)$ \\
\hline$\geq 30$ & $99(24.7)$ \\
\hline Mean (SD) & $28.0(3.6)$ \\
\hline \multicolumn{2}{|l|}{ Education level } \\
\hline Elementary school & $170(42.5)$ \\
\hline Guidance school & $37(9.3)$ \\
\hline High school & $74(8.5)$ \\
\hline Diploma and university & $119(29.7)$ \\
\hline \multicolumn{2}{|l|}{ Marital status } \\
\hline Married & $363(90.8)$ \\
\hline Divorced and widowed & $37(9.2)$ \\
\hline \multicolumn{2}{|l|}{ Number of children } \\
\hline$\leq 2$ & $131(32.8)$ \\
\hline $3-4$ & $219(54.7)$ \\
\hline$>5$ & $50(12.5)$ \\
\hline \multicolumn{2}{|l|}{ Number of family members } \\
\hline $1-3$ & 319 (79.7) \\
\hline$>3$ & $81(20.3)$ \\
\hline \multicolumn{2}{|l|}{ Sadat status } \\
\hline Sadat & $46(11.5)$ \\
\hline Non-Sadat & $354(88.5)$ \\
\hline \multicolumn{2}{|l|}{ Working Status } \\
\hline Housewife & $339(84.7)$ \\
\hline Working out & $61(15.3)$ \\
\hline \multicolumn{2}{|l|}{ Economic Status } \\
\hline Less than adequate & $99(24.7)$ \\
\hline Adequate & $301(75.3)$ \\
\hline \multicolumn{2}{|l|}{ Life satisfaction } \\
\hline Unsatisfied & $27(6.7)$ \\
\hline Satisfied & $212(53)$ \\
\hline No idea & $161(40.3)$ \\
\hline \multicolumn{2}{|l|}{ Having chronic diseases } \\
\hline Yes & $233(58.2)$ \\
\hline No & $167(41.8)$ \\
\hline
\end{tabular}

As the number of individuals with university degree was 12 , single cases $=2$, divorced $=2$, and subjects with more adequate income $=1$, so they were merged with the previous group.

responded with the results of the studies by Tehrani et al (19) and Enjezab et al (18) in Iran and Wattanasart (20) in Taiwan, and Duffy et al (21) in the United States. The samples of this study were in better status in comparison with Korean middle-aged women (22) and Turkish working women (23).
Table 2. Mean (SD) of the Total Score of Health Promoting Behaviors and the Sub-domains in Menopausal Women

\begin{tabular}{lcc}
\hline Variable & Mean (SD) & $\begin{array}{c}\text { Perceived Practical } \\
\text { Domain }\end{array}$ \\
\hline Health promoting behaviors & $2.6(0.3)$ & $1.4-3.6$ \\
Nutrition & $2.6(0.4)$ & $1 / 0-3.8$ \\
Physical activity & $1.6(0.3)$ & $1.0-3.2$ \\
Spiritual growth & $3.6(0.4)$ & $1.5-4 / 0$ \\
Health responsibility & $2.2(0.4)$ & $1.1-3.8$ \\
Stress management & $2.6(0.5)$ & $1.0-4.0$ \\
Interpersonal relations & $3.1(0.4)$ & $1.4-4 / 0$ \\
\hline
\end{tabular}

Table 3. The Relationship Between Health Promoting Behaviors and the Sub-domains and General Health

\begin{tabular}{lcc}
\hline Variable & $r$ & $P$ \\
\hline Health promoting behaviors & -0.23 & $<0.001$ \\
Nutrition & -0.23 & $<0.001$ \\
Physical activity & -0.18 & $<0.001$ \\
Spiritual growth & -0.35 & $<0.001$ \\
Health responsibility & -0.10 & $<0.001$ \\
Stress management & -0.23 & $<0.001$ \\
Interpersonal relations & -0.23 & $<0.001$ \\
\hline
\end{tabular}

In this study, the highest mean score of participants was related to spiritual growth. This result corresponded with the results of the studies by Enjezab et al on middle-aged women and Tol et al on university students (24). The score of women's spiritual growth in this study was more than the scores of the studies by Lee and Wang (25) in Taiwan and Duffy et al (21) in the United States. It seems that it is because of the role of religion in society of Islamic Iran. Spiritual growth is one of the important aspects of life and determines human's goals in life and increases the capabilities to promote health and life satisfaction (26). It also leads to a constant relationship between human's internal factors and is recognized by features like constancy in life, peace and feeling of good relationship with God and society and also individual's good relationship with her/ himself (27). During last decades, the WHO has focused on religious teachings and their effects on lifestyle of different societies especially Islamic countries and has asked health supervisors to carry out short-term and long-term programs to perform it (28).

The women in this study achieved the least score considering physical activity. This result corresponded with the results of the studies by Enjezab et al (18) and Tehrani et al (19) on middle-aged women and Mazloomi et al on professors of Yazd University of Medical Sciences (29). However, the results of the studies by Duffy et al (21) and Pender et al (30) in the Unites States, showed that participants were in better level of physical activity. The level of physical activity in this study was less than the level of physical activity on working women in Turkey and less than the results of the study by Lusk et al (31). It is necessary for middle-aged women to have physical activity because inactivity and inappropriate physical activity are the causes of cardiovascular diseases, diabetes and osteoporosis (32). The results of the study by Lopez-Alegria and 
De Lorenzi (33) showed that physical activity has positive effects on menopausal symptoms.

In this study, $24.7 \%$ of women were overweight (BMI $\geq 30$ ) as the result of inactivity and this reason paves the way for chronic diseases. In our society, the reason of inactivity may be lack of positive beliefs and attitudes toward physical activity. The experts believe that the individuals will carry out an action in the case of having positive attitude toward it (34). In this study, based on the results of data analysis, there was a reverse significant relationship between health promoting behaviors and the sub-domains and general health. The results is in line with the results of the study conducted by Samimi et al (35). It means that the participants of this study had disorders in general health because of inattention to health promoting behaviors and their dimensions. In the study by Ayronci et al (36) in 2005, it was showed that there was a significant relationship between general health and nutrition. In another study, Ezoe and Morimoto (37) showed a significant statistical relationship between general health and stress management. According to Stock et al (38) individuals with physical activity and social support had less health complaints. Misra and McKean (39) showed that there was a significant relationship between individual's health responsibility and general health.

Therefore, Ministry of Health and Medical Education should care about the middle-aged women like monitoring the pregnant women and under 6 children. They should set and perform education interventions of correct principles of life style. Because of the increase of life expectancy and disabilities in women, giving priority to the health of these people is very important in order to have a dynamic and healthy society.

\section{Suggestion}

Nowadays, the focus is on prevention and providing health by health promoting behaviors and also on omitting the factors with negative effects on general health level and most of the health problems such as overweight, cardiovascular diseases, different types of cancers, addiction, and psychological problems in all countries especially in developing countries, are in relation with individual's lifestyle change (40). The results of the present study show that individual's general health (physical-psychological) depends on health promoting behaviors; therefore, health promoting behaviors have most effect on providing general health.

\section{Ethical Issues}

Approval was obtained from the Ethics Committee of Research Deputy in Tabriz University of Medical Sciences (No. 91220).

\section{Conflict of Interests}

The authors declare no conflict of interests.

\section{Financial Support}

None.

\section{Acknowledgments}

Hereby, special thanks go to all the participants, Research Deputy of Tabriz University of Medical Sciences and Research and Health deputies of Gilan University of Medical Sciences.

\section{References}

1. Andrews GA. Promoting health and functioning in an aging population. Br Med J. 2000;322:728-9. doi:10.1136/ bmj.322.7288.728.

2. Dickey RA, Janick JJ. Lifestyle modifications in the prevention and treatment of hypertension. Endocr Pract. 2001;7(5):392-399. doi:10.4158/EP.7.5.392.

3. Mohammadi A, Fatemi S. The relationship between lifestyle and public health students at Rasht University of Medical Sciences in 2007. J Mazandaran Univ Med Sci 2007;25(5):145-156. [Persian].

4. Han U. Health promoting behavior and quality of life of chronic illness in Korea. International Nursing Library. http://www.nursinglibrary.org/vhl/handle/10755/157409.

5. Maher D, Harries AD, Zachariah R, Enarson D. A global framework for action to improve the primary care response to chronic non-communicable diseases: a solution to a neglected problem. BMC Public Health. 2009;9:355. doi:10.1186/1471-2458-9-355.

6. Walker SN, Sechrist KR, Pender NJ. The healthpromoting lifestyle profile: development and psychometric characteristics. Nurs Res. 1987;36(2):76-81.

7. Pender NJ, Walker SN, Sechrist KR, Stromberg MF. Predicting health promoting lifestyles in the workplace. Nurs Res. 1990;39(6):326-32.

8. Ghuorbani M, Azhari S, Esmaeili H. The survey of relationship between health promotion behaviors and vazomotuor's symptoms in menopausal women in Mashhad, Iran. IJOGI 2012;15(39):23-30.

9. Moilanen J, Aalto A-M, Hemminki E, Aro AR, Raitanen J, Luoto R. Prevalence of menopause symptoms and their association with lifestyle among Finnish middle-aged women. Maturitas. 2010;67(4):368-74. doi:10.1016/j. maturitas.2010.08.007.

10. Mohseni M. Medical Socialogy. Tehran: Tahmorys Publication; 2003. [Persian].

11. Parvizi S, Seyed Fatemi M, Kiani K. Family dynamism \& women's health. Women Social Psychologic Studies Quarterly. 2009;7(2):54-57.

12. Memarian R. Application of Nursing's Concepts \& Theories. Tehran: Tarbiat Modares University; 2000. [Persian].

13. Keyhani Z. Investigating the mental health status of women in Qazvin province. J Qazvin Univ Med Sci. 2011;15(11):5561. [Persian].

14. Foroud A, Mehdipour S. The effects of electro-acupuncture in postmenopausal women with hot flashes. Journal of Birjand university of Medical science 2010; 17(3). [Persian].

15. Shahrokhi A. General health status of female workers in Qazvin factories. J Qazvin Univ Med Sci. 2003;28:32-5.

16. Solhi M, Kazemi SS, Haghni H. Relationship between general health and self-efficacy in women referred to health center No. 2 in Chaloos (2012). Razi J Med Sci 2012;20(109):72-79.

17. Karaçam Z, Şeker SE. Factors associated with menopausal symptoms and their relationship with the quality of life among Turkish women. Maturitas. 2007;58(1):75-82. 
doi:10.1016/j.maturitas.2007.06.004.

18. Enjezab B, Farajzadegan Z, Taleghani F, Aflatoonian A, Morowatisharifabad MA. Health promoting behaviors in a population-based sample of middle-aged women and its relevant factors in Yazd, Iran. Int J Prev Med. 2010;3(suppl1):S191.

19. Tehrani G, Ghobadzadeh M, Arasto M. The health promotion in menopausal women with educational based on model of self care, Tehran. Hayat. 2007;13(3):67-75.

20. Wattanasart T. Factors affecting health-promoting behaviors of menopausal women attending menopausal clinic in Chantaburi-province [dissertation]. Thailand: Mahidol University; 2003.

21. Duffy ME, Rossow R, Hernandez M. Correlates of healthpromotion activities in employed Mexican American women. Nurs Res. 1996;45(1):18-24.

22. Shin HS, Lee J, Lee KH, Song YA. Health behavioral patterns associated with psychologic distress among middle-aged Korean women. Asian Nurs Res. 2007;1(1):617. doi:10.1016/S1976-1317(08)60009-2.

23. Beser A, Bahar Z, Büyükkaya D. Health promoting behaviors and factors related to lifestyle among Turkish workers and occupational health nurses' responsibilities in their health promoting activities. Ind Health. 2007;45(1):151-159. doi:10.2486/indhealth.45.151.

24. Tol A, Tavassoli E, Shariferad GR, Shojaezadeh D. The relation between health-promoting lifestyle and quality of life in undergraduate students at school of health, Isfahan University of Medical Sciences. Health System Research. 2011;7(4).

25. Lee FH, Wang HH. A preliminary study of a healthpromoting lifestyle among Southeast Asian women in Taiwan. Kaohsiung J Med Sci. 2005;21(3):114-120. doi:10.1016/S1607-551X(09)70287-6.

26. Al Ma'Aitah R, Haddad L, Umlauf MG. Health promotion behaviors of Jordanian women. Health Care Women Int. 1999;20(6):533-546. doi:10.1080/073993399245449.

27. Adegbola M. The relationship among spirituality, selfefficacy, and quality of life in adults with sickle cell disease. Nurs Health Sci. 2008;12:275-279.

28. WHO. Health promotion through Islamic lifestyles the amman declaration. Geneva: WHO; 2012

29. Mazloomi MS, Fazelpour S, Askarshahi M. Healthpromoting behaviors and psychosocial Well-Being of University Shahid Sadoqi Yazd Academic Staff in Iran. Journal of Ilam University of Medical Sciences. 2013;21(3):12-21. [In Persian].

30. Pender NJ, Murdaugh CL, Parsons MA. Health promotion in nursing practice. 6th ed. USA: Upper Saddle River. Prentice Hall; 2010.

31. Lusk SL, Kerr MJ, Ronis DL. Health-promoting lifestyles of blue-collar, skilled trade, and white-collar workers. Nurs Res. 1995;44(1):20-4.

32. Ekelund U, Besson H, Luan J, et al. Physical activity nand gian in abdominal adiposity and body weight. Prospective cohort study in 288,498 men and women. Am J Clin Nutr. 2011;93(4):826-835. doi:10.3945/ajcn.110.006593.

33. Lopez-AlegriaF,De Lorenzi D. [Lifestyles and quality oflife of post menopausal women]. Rev Med Chil. 2011;139(5):618624. doi:10.4067/S0034-98872011000500009.

34. Ghazanfari Z. The effect of TTM \& HPM to promote physical activity among diabetic women. Tehran: Tarbiat Modarres University; 2009.

35. Samimi R, Masrour D, Hosseini F, Tamaddonfar M. Health promoting behaviors and its relationship with general health in university students. J Nurs Iran. 2007;19(48):4-9.

36. Ayranci U, Son N, Son O. Prevalence of nonvitamin, nonmineral supplement usage among students a Turkish university. Public Health. 2005;5(47):1-10.

37. Ezoe S, Morimoto K. Behavioral lifestyle and mental health status of Japanese factory workers. Prev Med. 1994;23(1):98105. doi:10.1006/pmed.1994.1014.

38. Stock C, Kücük N, Miseviciene I, et al. Differences in health complaints among university students from three European countries. Prev Med. 2003;37(6):535-543. doi:10.1016/j. ypmed.2003.07.001.

39. Misra R, McKean M. College students' academic stress and its relation to their anxiety, time management, and leisure satisfaction. Am J Health Stud. 2000;16(1):41.

40. Edlin G, Golanty E. Health and Wellness. 8th ed. Boston: Jones and Bartlet; 2004.

Copyright ( 2017 The Author (s); This is an open-access article distributed under the terms of the Creative Commons Attribution License (http://creativecommons.org/licenses/by/4.0), which permits unrestricted use, distribution, and reproduction in any medium, provided the original work is properly cited. 